Whilst pure pellucid marginal degeneration is a relatively rare corneal ectasia, it can be viewed as part of a spectrum of disease including keratoconus and keratoglobus. It is hoped that this article may stimulate thought and possible change in practice for surgeons tackling these problems. Unfortunately in these days of active cost-cutting in health care it has become increasingly difficult to obtain data on longterm follow-up of the results of treatment for these conditions, but it is only through collection and documentation of this information that we can rationally choose the appropriate treatment for patients who are looking for more than a shortterm solution to their condition.

St George's Hospital

London

\section{References}

1. The Collaborative Corneal Transplantation Studies Research Group. The Collaborative Corneal Transplantation Studies (CCTS). Effectiveness of histocompatibility matching in high-risk corneal transplantation. Arch Ophthalmol 1992;110:1392-403.

2. Flowers CW, Chang KY, McLeod SD, Irvine JA, McDonnell PJ, Rao N, Smith RE. Changing indications for penetrating keratoplasty, 1989-1993. Cornea 1995; 14:583-8.

3. McLean H, Robinson LP, Weschler AW. Long-term results of corneal wedge excision for pellucid marginal degeneration. Eye 1997;11:613-7.

4. Olsen T, Dam-Johansen M. Evaluating surgically induced astigmatism. J Cataract Refract Surg 1994; 20:517-22.

5. Bradley AB, Drews-Botch C, Gemmill M, Guell J, Murad M, Waring GO. Complications of Mersilene sutures in penetrating keratoplasty. Refract Corneal Surg 1992;8:296-305.

\title{
PREVENTING VISUAL IMPAIRMENT IN PRE-TERM BABIES
}

If it is the business of an ophthalmologist to prevent blindness, it must be the business of a paediatric ophthalmologist to prevent childhood blindness. In the UK most of the causes of childhood blindness are not easily preventable, but one group - premature babies - deserves our attention because they are at much higher risk of visual impairment than their peers and it is likely that much of this is preventable. Premature infants are at risk of visual impairment from retinopathy of prematurity (ROP), nystagmus, cortical problems, and high myopia. ${ }^{1}$ They are also at high risk of strabismus.

Primary prevention of these problems would be by lowering the incidence of prematurity, but there is little evidence that this is occurring. The rise in assisted conception, which appears to predispose to prematurity and to $\mathrm{ROP},{ }^{2}$ is likely to increase the incidence in the UK, and ROP appears to be a growing problem worldwide.

The paper by Pennefather et al. in this issue $e^{3}$ is the most comprehensive study of the long-term refraction of premature infants yet done. It seems from this study that the myopia associated with prematurity is itself the result of ROP and not of the prematurity per se. Some of this myopia is likely to be due to the effects of cryotherapy treatment for the ROP.

It is almost 10 years since the first published results of the Cryo-ROP study, ${ }^{4}$ which clearly showed that retinal cryotherapy could reduce the incidence of blindness in children with ROP. Following this, mass screening programmes have been initiated with the intention of treating at-risk infants. In this period laser retinal photocoagulation has become popular with many ophthalmologists since it seemed to produce less immediate problems than did cryotherapy. The indirect delivery system of first the argon laser and, more recently, the diode laser, has meant that it is quite feasible to laser the peripheral retina in pre-term babies, and this treatment has not only been shown to result in less myopia than cryotherapy ${ }^{5}$ but may also be superior to cryotherapy in its ability to control the disease. ${ }^{6}$

Although laser photocoagulation can be delivered with topical anaesthesia, it is probably better to give the infant a general anaesthetic since this not only gives control over ventilation but also provides adequate analgesia. A recent study has confirmed the long-held suspicion that invasive procedures performed on neonates without analgesia can produce long-lasting adverse psychological effects. ${ }^{7}$

Despite this improvement in the treatment of cicatricial ROP, the visual results following treatment are not good. For example, in the study by Pennefather et al., retinal detachment occurred in 4 of the 27 eyes that developed cicatricial ROP, and 8 of these 27 had not been screened for the development of ROP. In White and Repka's paper, ${ }^{5}$ of the 12 eyes treated with laser only one had an acuity recordable as $6 / 6$ and 4 had myopia of over 10 dioptres. These results are not unusual, and would fit with most surgeons' experience. Can we do better? If Pennefather et al. were to repeat their studies in 10 years' time would the incidence of retinal detachment and myopia be lower?

The original treatment threshold was set in the Cryo-ROP study as being that degree of ROP at which roughly $50 \%$ of the patients could be expected to progress to blindness, and this was done for the 
purposes of being able to demonstrate an effect of the treatment in this particular trial, studying a disease which has a high spontaneous remission rate. Most parents, however, would wish their child to be treated at a much lower level of risk. The threshold for treatment ought to be set at that level at which the benefits from treatment outweigh its risks. We have learned much about the natural history of ROP - a very unpredictable disease - but we know little of the risks to the infant from treatment. What are the risks from anaesthesia? What are the adverse effects on the eye from the peripheral retinal ablation? We know that laser has fewer of these than cryotherapy but still know little about the long-term consequences on the patients' visual acuities and fields. The treatment threshold for ROP probably has been set too high; further studies on the outcomes of treatment are needed to discover at what level it ought to be set.

Queen's Medical Centre

Nottingham

\section{References}

1. Escobar GJ, Littenberg B, Petitti DB. Outcome among surviving very low birthweight infants: a meta-analysis. Arch Dis Child 1991;66:204.

2. McKibbin M, Dabbs TR. Assisted conception and retinopathy of prematurity. Eye 1996;10:411-530.

3. Pennefather $\mathrm{P}$, et al. Refractive errors in children born before 32 weeks gestation. Eye 1997;11:736-43.

4. Cryotherapy for Retinopathy of Prematurity Cooperative Group. Multicentre trial of cryotherapy for retinopathy of prematurity: preliminary results. Arch Opthalmol 1988;106:471-9.

5. Algawi K, Goggin M, O'Keefe M. Refractive outcome following diode laser versus cryotherapy for eyes with retinopathy of prematurity. Br J Ophthalmol 1994;78: $612-4$.

6. White JE, Repka MX. Randomised comparison of diode laser photocoagulation versus cryotherapy for threshold retinopathy of prematurity: a 3-year outcome. J Paediatr Ophthalmol Strabismus 1997;34:83-7.

7. Taddio A, Katz J, Ilersich AL, Koren G. Effect of neonatal circumcision on pain response during subsequent routine vaccination. Lancet 1997;349:599-603.

\section{AN OUNCE OF PREVENTION IS WORTH A POUND OF CURE?}

The fascinating paper by Claridge and her colleagues in this issue ${ }^{1}$ on the medical suppression of active dysthyroid eye disease should cause all of us who see such patients to reassess our approach to them.

The study concerns 40 consecutive patients with active thyroid eye disease who were treated aggressively with immunosuppression, using primary orbital radiotherapy, azathioprine and corticosteroids. Patients had activity assessed with the Mourits and total eye scores before and after treatment, in addition to a full clinical examination including uniocular fields of fixation - a measure of absolute ocular motility, rather than a comparative technique such as a Hess chart.

Over an average period of 1.2 years, the eye disease became inactive, and treatment was well tolerated. One patient $(2.5 \%)$ required subsequent orbital decompression for cosmetic reasons, $6(15 \%)$ had strabismus surgery, and $13(32.5 \%)$ required minor lid surgery.

These are impressive figures, and are made even more so by the authors' contention that their treatment regime leads to a fourfold reduction in the requirement for subsequent orbital decompression and strabismus surgery. Regrettably, however, this figure is derived by comparison of their figures with those of Prummel et al. ${ }^{2}$ who may have applied an entirely different set of clinical criteria for their surgical interventions.
Also worthy of note in this context is the interesting series of papers by Bartley et $a l^{3-5}$ analysing an incidence cohort of 120 patients from Olmstead County, Minnesota, and derived from the computerised database at the Mayo Clinic. This cohort was collected over a period between 1976 and 1990, so management criteria might have changed. It is also evident that many patients had mild disease. However, 6 cases $(5 \%)$ received steroids for optic neuropathy, with 5 going on to orbital decompression, and 3 others $(2.5 \%)$ had primary orbital decompression. The strabismus surgery rate was $9.2 \%$, and the lid surgery rate $12.5 \%$. It is again unclear what criteria were applied for subsequent surgical intervention.

It seems unlikely that different groups of authors will be able to agree completely on the indications for surgery, in particular orbital decompression for reasons of cosmetic improvement and strabismus surgery for small deviations and head postures, and so until the treatment of cases of this most unpleasant and disabling disease can be analysed in a randomised controlled clinical trial, we will not know whether the use of immunosuppression to abort the ocular manifestations is as effective as Claridge and her colleagues clearly believe it to be. One hopes that such a trial will not be long overdue.

Moorfields Eye Hospital London
John Lee 